\title{
Pre-emptive and therapeutic value of blocking bacterial attachment to the endothelial alphaVbeta3 integrin with cilengitide in sepsis
}

\author{
Carolina D. Garciarena', Tony M. McHale ${ }^{1}$, Ignacio Martin-Loeches ${ }^{2}$ and Steve W. Kerrigan ${ }^{1,3^{*}}$
}

Sepsis is a fast progressing disease, triggered by the host response to infection. If untreated, sepsis can rapidly evolve to multi-organ dysfunction and septic shock [1]. Despite numerous advances in palliative intensive care and antibiotic treatment, sepsis remains a major cause of morbidity and mortality [2]. The lack of effective therapies making it to market is due to our poor understanding of the early mechanisms driving sepsis.

The vascular endothelium is a major target of sepsis-induced events [2, 3]. Upon entry to the bloodstream, bacteria attach to the endothelium within $15 \mathrm{~s}$ [4]. Attachment triggers dysregulated signals that result in endothelial cell (EC) death and loss of barrier integrity, which give rise to increased capillary permeability clinically associated with hypotension, subcutaneous and body-cavity oedema and impaired tissue oxygenation, key events leading to multi-organ failure.

We have recently reported bacterial binding to the major EC integrin $\alpha \mathrm{V} \beta 3$ as a novel host-pathogen interaction that occurs early in sepsis [4, 5]. By this mechanism, both Staphylococcus aureus and Escherichia coli (primary triggers of sepsis) induce loss of junction protein VE-cadherin, which weakens the EC barrier and increases permeability. We identified that blocking $\alpha v \beta 3$ with cilengitide prevents bacterial binding and attenuates EC injury $[4,5]$ when given prior to bacterial challenge. To ascertain if cilengitide would be useful post-bacterial attachment we perfused clinical strains of $S$. aureus or $E$. coli over human ECs for $360 \mathrm{~s}$ using a real time ex vivo model of sepsis. Cilengitide $(0.05 \mu \mathrm{M})$ was either coadministered with the bacteria from $\mathrm{t}=0 \mathrm{~s}$ (pre-emptive effect) or introduced to the suspension at $t=15,30$ and $180 \mathrm{~s}$ (therapeutic effect).

Our data demonstrate that $S$. aureus and E. coli binding to ECs increases steadily over time (Fig. 1). When applied at $\mathrm{t}=0$, cilengitide $(0.05 \mu \mathrm{M})$ completely abolished $S$. aureus and $E$. coli attachment to ECs. Following bacterial attachment to ECs (at $\mathrm{t}=15$, 30 and $180 \mathrm{~s}$ ), cilengitide significantly displaced bound bacteria in a time-dependent manner, rapidly reducing bacterial load back to background levels.

These results suggest that cilengitide is capable of competitively antagonizing bacterial binding to ECs and as a result removes the signal that perpetuates vascular EC involvement in sepsis, and thus presents as a potential as new complementary strategy for the treatment of established sepsis and as prophylaxis in high risk patients. These observations warrant the initiation of preclinical and human clinical trials to validate the use of cilengitide as a pharmacological tool to reduce risk and/or increase the time window for decision-making in sepsis patients.

\footnotetext{
* Correspondence: skerrigan@rcsi.ie

${ }^{1}$ Cardiovascular Infection Research Group, Irish Centre for Vascular Biology,

Royal College of Surgeons in Ireland, Dublin 2, Ireland

${ }^{3}$ Cardiovascular Infection Research Group, Royal College of Surgeons in

Ireland, 123 St. Stephen's Green, Dublin 2, Ireland

Full list of author information is available at the end of the article
} 
a

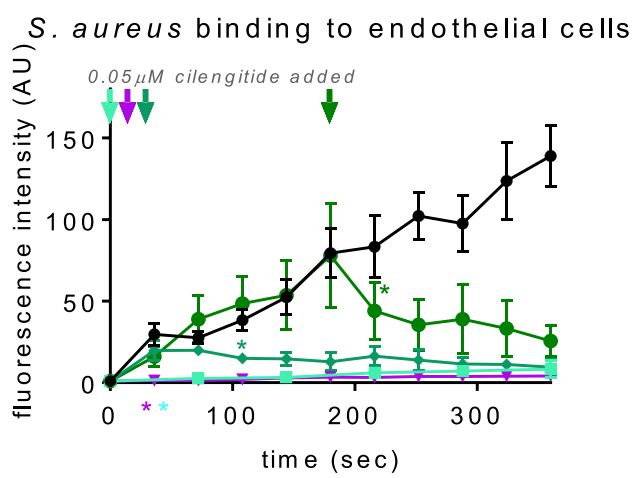

b

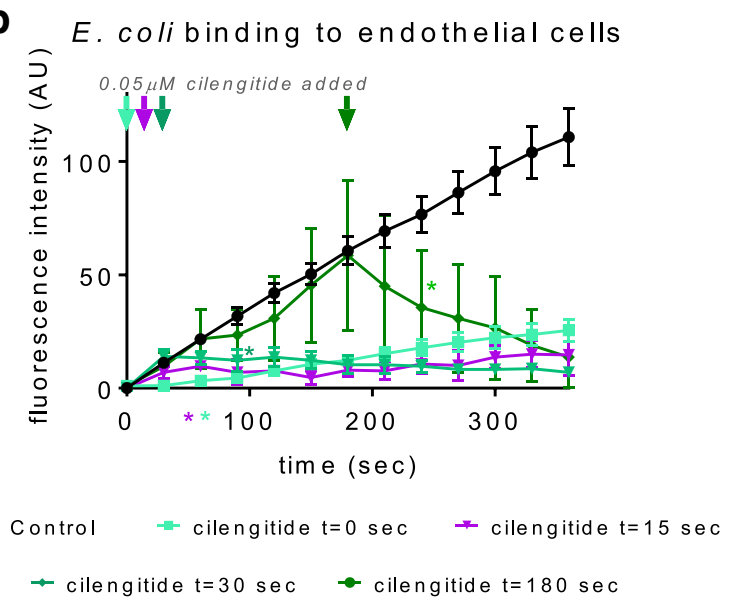

Fig. 1 S. aureus (a) and E. coli (b) binding to EC monolayers under flow. S. aureus and E. coli were labelled with fluorescein. Bacterial suspensions were perfused through Ibidi chambers over confluent EC monolayers and timelapse bacterial binding was measured by fluorescence microscopy. Bacteria binding to EC was assessed in the presence or absence of cilengitide. Cilengitide was added at different time points (indicated by arrows): $t=0 \mathrm{~s}, \mathrm{t}=15 \mathrm{~s}, \mathrm{t}=30 \mathrm{~s}$ and $t=180 \mathrm{~s}(\mathrm{n}=3-6$ for $\mathrm{S}$. aureus and $\mathrm{n}=3-11$ for $E$. coli). Asterisks indicate that results are different from control form that point onwards, $P<0.05$

\section{Abbreviation}

EC: Endothelial cell

\section{Acknowledgments}

Not applicable.

\section{Funding}

This publication was funded by Science Foundation Ireland (SFI) under grant number 13/CDA/2119 (SWK)

\section{Availability of data and materials}

All data generated or analysed during this study are included in this published article.

\section{Authors' contributions}

CDG, IML and SWK conceived and designed the experiments. CDG and TMMH acquired and analysed data. CDG and SWK wrote the manuscript. All authors read and approved the final manuscript.

Ethics approval and consent to participate Not applicable.

\section{Consent for publication}

Not applicable.

\section{Competing interests}

The authors declare that they have no competing interests.

\section{Publisher's Note}

Springer Nature remains neutral with regard to jurisdictional claims in published maps and institutional affiliations.

\section{Author details}

${ }^{1}$ Cardiovascular Infection Research Group, Irish Centre for Vascular Biology, Royal College of Surgeons in Ireland, Dublin 2, Ireland. ${ }^{2}$ Trinity Centre for Health Sciences, St. James University Hospital, Dublin 8, Ireland. ${ }^{3}$ Cardiovascular Infection Research Group, Royal College of Surgeons in Ireland, 123 St. Stephen's Green, Dublin 2, Ireland.

Received: 23 August 2017 Accepted: 7 September 2017

Published online: 26 September 2017

\section{References}

1. Angus DC, van der Poll T. Severe sepsis and septic shock. N Engl J Med. 2013;369(21):2063.

2. Goldenberg NM, et al. Broken barriers: a new take on sepsis pathogenesis. Sci Transl Med. 2011;3(88):88ps25.

3. Fleischmann C, et al. Assessment of global incidence and mortality of hospital-treated sepsis. current estimates and limitations. Am J Respir Crit Care Med. 2016;193(3):259-72.

4. McDonnell CJ, et al. Inhibition of major integrin alphaV beta3 reduces Staphylococcus aureus attachment to sheared human endothelial cells. J Thromb Haemost. 2016;14(12):2536-47.

5. McHale TM, et al. Major endothelial cell integrin aV $\beta 3$ as a target in gramnegative sepsis caused by urinary tract infection. Res Pract Thromb Haemostasis. 2017;1(Supplement S1):1420. 